\title{
Pengembangan Media Belajar Model-Model Boneka Dari Bahan Kain Flanel Berdasarkan Tema Kegiatan untuk Pembelajaran Anak Usia Dini
}

\author{
Usep Kustiawan, Wuri Astuti, Munaisra Tri Tirtaningsih \\ Pendidikan Guru Anak Usia Dini, Universitas Negeri Malang
}

\section{Edcomtech}

Jurnal Kajian

Teknologi Pendidikan

Volume 5, No 2, Oktober 2020

137-144

Submitted 27-01-2020

Accepted 30-04-2020

Corresponding Author

Usep Kustiawan

usep.kustiawan.fip@um.ac.id

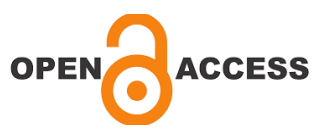

\begin{abstract}
Abstrak
Pemanfaatan media pembelajaran yang tepat di TK dapat mengembangkan berbagai kemampuan anak dengan baik, tetapi sebaliknya apabila penggunaan media kurang menarik bagi anak, anak akan cepat bosan dan tidak tertarik lagi dengan pembelajaran yang diberikan oleh guru. Tujuan penelitian ini adalah untuk mengembangkan media pembelajaran model-model boneka yang dapat digunakan untuk mengembangkan kemampuan bahasa ekspresif anak dalam bercerita sesuai dengan jenis tema kegiatan yang ada di TK.. Penelitian ini merupakan penelitian pengembangan yang mengadopsi tahapan pengembangan dari Borg and Gall. Hasil penelitian menunjukkan bahwa produk media yang dikembangkan mudah digunakan siswa dan memiliki tingkat kemenarikan yang tinggi.
\end{abstract}

Kata kunci: model belajar boneka, tema kegiatan, pembelajaran bahasa AUD

\begin{abstract}
The use of appropriate learning media in kindergarten can develop a variety of children's abilities well, but conversely, if the use of media is less attractive to children, children will quickly get bored and are no longer interested in learning provided by the teacher. The purpose of this research is to develop learning media for doll models that can be used to develop children's expressive language skills in storytelling in accordance with the types of theme activities that exist in kindergarten. This research is a research development that adopts the development stages of Borg and Gall. The results showed that the developed media products were easy for students to use and had a high level of attractiveness.
\end{abstract}

Keywords: puppet learning models, theme activities, early childhood language learning 


\section{PENDAHULUAN}

Taman kanak-kanak (TK) sebagai lembaga PAUD formal mendasari pembentukan kepribadian manusia secara utuh, yaitu untuk pembentukan karakter, budi pekerti luhur, cerdas ceria, terampil, dan bertakwa kepada Tuhan Yang Maha Esa. Anak usia dini berada pada masa yang paling optimal untuk berkembang. Pada masa ini anak mempunyai rasa ingin tahu yang sangat besar dan melakukan apapun untuk memenuhi rasa ingin tahunya (Mutiah, 2015).

Selain itu anak secara naluriah selalu aktif bergerak, akan menguji kemana saja sesuai dengan kemampuan, minat, dan kesenangan. Muatan kurikulum 2013 Pendidikan Anak Usia Dini berisi program-program pengembangan, yang terdiri: (1) program pengembangan nilai agama dan moral; (2) program pengembangan fisik motorik; (3) program pengembangan kognitif; (4) program pengembangan bahasa; (5) program pengembangan sosialemosional; (6) program pengembangan seni (Dini, 2015; Pratiwi, 2017; Sujiono, 2009). Program pengembangan dimaksud adalah perwujudan suasana belajar untuk berkembangnya perilaku, kematangan berpikir, kinestetik, bahasa, sosial emosional, dan bahasa melalui kegiatan bermain.

Suasana belajar diartikan segala sesuatu yang dapat mendorong minat anak untuk belajar. Pemanfaatan media pembelajaran yang tepat di TK dapat mengembangkan berbagai kemampuan anak dengan baik (Arsyad, 2002). Dan sebaliknya apabila penggunaan media kurang menarik bagi anak, anak akan cepat bosan dan tidak tertarik lagi dengan pembelajaran yang diberikan oleh guru.

Istilah media dalam pembelajaran tidak dapat dipisahkan dari sumber belajar. Keduanya menunjuk pada satu obyek serupa. Jika obyek tersebut difungsikan, ia disebut media; sedangkan "bendanya" sendiri disebut sumber belajar. Istilah sumber dan media pembelajaran sering dipakai secara campur aduk, berganti-ganti, kadang, kadangkadang bersamaan (Akbar, 2013). Pengertian sumber belajar adalah segala macam yang dapat memberikan informasi maupun berbagai ketrampilan pada anak/murid, sehingga memudahkan pembelajaran anak/ murid (Ghafur, 1998; Satrianawati, 2018; Sudono, 1995). Association of Education and Communication Technology (AECT) memberikan batasan bahwa media sebagai segala bentuk dan saluran yang digunakan untuk menyalurkan pesan/informasi (AECT, 1977).

Media pembelajaran adalah segala sesuatu yangdigunakanolehguruuntukmenyampaikan materi pelajaran kepada murid sehingga murid jadi tertarik minat dan perhatiannya, terangsang pikiran dan perasaannya, dalam proses pembelajaran untuk mencapai tujuan pembelajaran (Kustiawan, 2017; Kustiawan et al., 2015; Ramadhani \& Kustiawan, 2017; Setyosari, 2005; Susilana, Si, \& Riyana, 2008). Media memiliki kegunaan untuk mengatasi keragaman latar belakang siswa sehingga media dapat memberikan perangsang, pengalaman, dan menimbulkan persepsi yang sama (Arief, 2009; Sadiman, Arief S, Rahardjo, Haryono, Anung, 1986; Sadiman, 2010).

Media pembelajaran pada pendidikan anak usia dini memiliki karakteristik yang unik. Para pengembang media harus memperhatikan prinsip-prinsip penting terkait anak usia dini. Sebagai anak balita, maka aspek kemenarikan media merupakan hal penting yang harus diperhatikan. Di samping itu aspek lainnya adalah unsur kemudahan dalam penggunaannya. Aspek lain yang harus diperhatikan adalah unsur keamanan untuk digunakan (Kustiawan, 2016; Ulfa, 2017).

Penelitian ini bertujuan untuk mengembangkan media belajar berupa boneka menggunakan bahan kain flanel yang dirancang berdasarkan tema kegiatan untuk pendidikan anak usia diri yang layak dan menarik. Manfaat dari penelitian ini adalah untuk membantu para guru dan peserta didik agar dapat menikmati proses pembelajaran yang menarik dan menyenangkan.

\section{METODE}

Metode penelitian yang dilakukan ini menggunakan penelitian dan pengembangan Research \& Development (R\&D) (Sugiyono, 2014). Penelitian ini dilakukan di Lembaga PAUD Gugus 9 Kelurahan Bandulan Kecamatan Sukun Kota Malang. Prosedur penelitian dan 
pengembangan media pembelajaran modelmodel boneka ini menggunakan prosedur penelitian dan pengembangan Borg and Gall yang terdiri dari sepuluh langkah yang disesuaikan dengan subjek dan lapangan yang dihadapi. Oleh karena itu, peneliti memodifikasi menjadi 7 tahapan yakni:1) penelitian dan pengumpulan informasi, 2) perencanaan, 3) Pengebangan Produk, 4) Validasi dan Uji coba produk awal, 5)Revisi produk, 6) Uji coba lapangan, 7) revisi produk akhir (Ardhana, 2002; Bennett, Borg, \& Gall, 1984; Gall, Borg, \& Gall, 2003).

Teknik analisis data adalah teknik analisis kualitatif dan kuantitatif berupa persentase. Analisis kualitatif digunakan untuk menganalisis pengumpulan data dari para ahli dengan menggunakan data kualitatif. Analisis kuantitatif berupa persentase digunakan untuk mengetahui hasil pengumpulan data pada penelitian awal (analisis kebutuhan dari para ahli), hasil uji coba kelompok kecil dan hasil uji coba lapangan (kelompok besar). Penarikan kesimpulan hasil penelitian didasarkan pada hasil analisis data kuantitatif dan kualitatif dari berbagai sumber.

\section{HASIL DAN PEMBAHASAN}

Produk yang dikembangkan dalam penelitian dan pengembangan ini yaitu model-model boneka berupa boneka jari, dan boneka tangan, yang terbuat dari bahan utama kain flanel dengan ukuran yang disesuaikan dengan jenis model bonekanya. Model-model boneka ini bentuknya sesuai dengan tema kegiatan yaitu tema keluarga, tema tanaman, dan tema binatang. Hasil tinjauan dari para ahli digunakan sebagai dasar dalam melakukan revisi awal terhadap rancangan produk media pembelajaran model-model boneka yang dikembangkan.

Tinjauan dilakukan oleh tiga orang ahli, yakni satu ahli pembelajaran anak usia dini, satu ahli media pembelajaran anak usia dini, dan satu ahli tema kegiatan pembelajaran anak usia dini. Tinjauan para ahli bertujuan untuk mengetahui kesesuaian produk yang dikembangkan dengan kebutuhan yang ada di lapangan. Hasil dari penelitian pengembangan berdasarkan analisis data kuantitatif diperoleh persentase sebesar $87,5 \%$ dari ahli pembelajaran anak usia dini, dan $89,58 \%$ dari ahli media pembelajaran anak usia dini, dan $85,41 \%$ dari ahli tema kegiatan pembelajaran anak usia dini. Secara umum data hasil evaluasi menurut para ahli memperoleh hasil sebagai berikut:

Tabel 1. Keseluruhan Data Hasil Evaluasi para Ahli

\begin{tabular}{lll}
\hline No. & Ahli Evaluasi & Persentase \\
\hline 1. & Ahli Pembelajaran Anak Usia Dini & $87,5 \%$ \\
\hline 2. & $\begin{array}{l}\text { Ahli Media Pembelajaran Anak } \\
\text { Usia Dini }\end{array}$ & $\mathbf{8 9 , 5 8 \%}$ \\
\hline 3. & Ahli Tema Kegiatan Pembelajaran & $\mathbf{8 5 , 4 1 \%}$ \\
& Anak Usia Dini & \\
\hline & Rata-rata & $\mathbf{8 7 , 4 9 \%}$ \\
\hline
\end{tabular}

Dari keseluruhan data hasil evaluasi para ahli diperoleh rata-rata persentase sebesar $87,49 \%$, berdasarkan kriteria kelayakan di Bab III maka media pembelajaran modelmodel boneka dari bahan kain flanel dapat dikatakan sangat valid atau layak digunakan.

Hasil uji coba kelompok kecil terhadap produk awal media pembelajaran modelmodel boneka dari bahan kain flanel diperoleh dari hasil observasi tentang aspek kemenarikan, kemudahan, dan keamanan anak dalam kegiatan menggunakan media pembelajaran model-model boneka dari bahan kain flanel yang dilakukan oleh guru kelas dengan subjek 6 anak kelompok B TK PKK, TK AGAPE, TK PLUS KIDS kelurahan Bandulan kecamatan Sukun kota Malang.

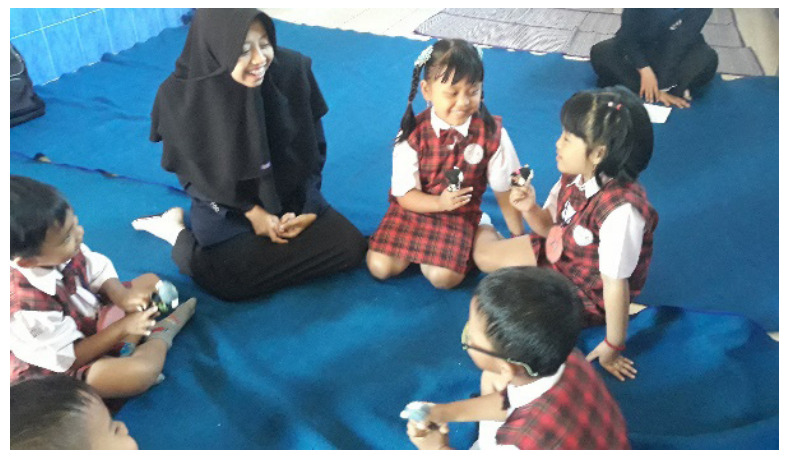

Gambar 1. Kegiatan Uji Coba Kelompok Kecil di Kelas B TK PKK Kelurahan Bandulan Kecamatan Sukun Kota Malang. 


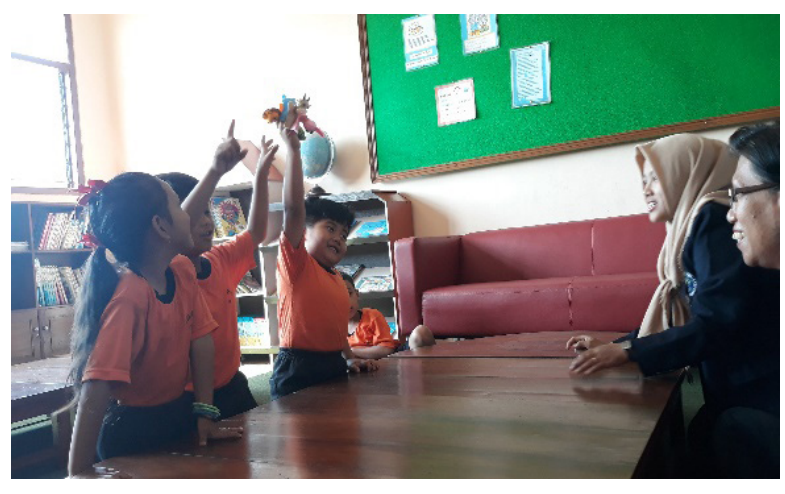

Gambar 2. Kegiatan Uji Coba Kelompok Kecil di Kelas B TK AGAPE Kelurahan Bandulan Kecamatan Sukun Kota Malang

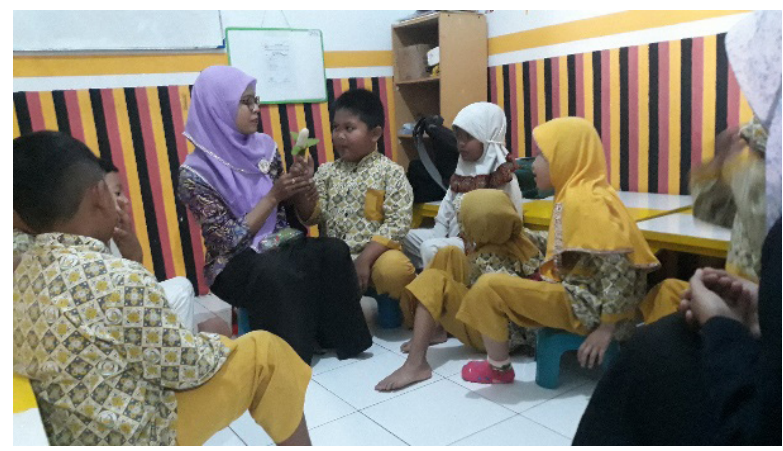

Gambar 3. Kegiatan Uji Coba Kelompok Kecil di Kelas B TK PLUS KIDS Kelurahan Bandulan Kecamatan Sukun Kota Malang

Hasil analisis data uji coba kelompok kecil dalam pengembangan media pembelajaran boneka dari bahan kain flanel di TK PKK, TK AGAPE, TK PLUS KIDS Bandulan kota Malang terkait aspek kemudahan diperoleh persentase sebesar $83,32 \%$ anak mudah menggunakan media pembelajaran boneka dari bahan kain flanel, terkait aspek kemenarikan diperoleh persentase sebesar $98,05 \%$ anak tertarik menggunakan media pembelajaran boneka dari bahan kain flanel, serta terkait aspek keamanan diperoleh persentase sebesar $100 \%$ anak aman dalam menggunakan media pembelajaran boneka dari bahan kain flanel. Berdasarkan keseluruhan data hasil uji coba kelompok kecil diperoleh rata-rata persentase sebesar 93,79\%, dari kriteria yang digunakan maka dapat dikatakan media pembelajaran boneka dari bahan kain flanel sangat valid atau layak digunakan
Tabel 2. Rekap Keseluruhan Data Hasil Uji Coba Kelompok Kecil

\begin{tabular}{|c|c|c|}
\hline No. & $\begin{array}{l}\text { Evaluasi } \\
\text { TK PKK } \\
\text { TK AGAPE } \\
\text { TK PLUS } \\
\text { KIDS }\end{array}$ & $\begin{array}{l}\text { RATA } \\
\text { RATA }\end{array}$ \\
\hline 1. & $\begin{array}{l}\text { Aspek Kemudahan } \\
83,33 \% \\
74,99 \% \\
91,66 \%\end{array}$ & $83,32 \%$ \\
\hline 2. & $\begin{array}{l}\text { Aspek Kemenarikan } \\
100 \% \\
100 \% \\
94,16 \%\end{array}$ & $98,05 \%$ \\
\hline 3. & $\begin{array}{l}\text { Aspek Keamanan } \\
100 \% \\
100 \% \\
100 \%\end{array}$ & $100 \%$ \\
\hline & $\begin{array}{l}\text { Jumlah } \\
283,33 \\
274,99 \\
285,82\end{array}$ & 281,37 \\
\hline & $\begin{array}{l}\text { Rata-rata } \\
94,44 \% \\
91,66 \% \\
95,27 \%\end{array}$ & $93,79 \%$ \\
\hline & $\begin{array}{l}\text { Jumlah } \\
281,37\end{array}$ & \\
\hline & $\begin{array}{l}\text { Rata-rata } \\
93,79 \%\end{array}$ & \\
\hline
\end{tabular}

Berdasarkan keseluruhan data hasil uji coba kelompok kecil diperoleh rata-rata persentase sebesar 93,79\%, dari kriteria yang digunakan maka dapat dikatakan media pembelajaran boneka dari bahan kain flanel sangat valid atau layak digunakan. Dengan demikian dapat dikatakan media pembelajaran boneka dari bahan kain flanel layak digunakan untuk mengembangkan kemampuan bahasa ekspresif anak dalam bercerita, serta peneliti dapat melanjutkan ke tahap uji coba lapangan (kelompok besar).

Selanjutnya yaitu hasil tahap uji coba lapangan (kelompok besar) dilakukan dengan subjek 15 - 20 anak kelompok B TK PKK, TK AGAPE, TK PLUS KIDS Bandulan kecamatan 
Sukun kota Malang. Hasil uji coba lapangan (kelompok besar) diperoleh dari rata-rata dari observasi terkait dengan aspek kemudahan, kemenarikan, dan keamanan anak dalam penggunaan media pembelajaran boneka dari bahan kain flanel yang dilakukan oleh guru kelas kelompok B.

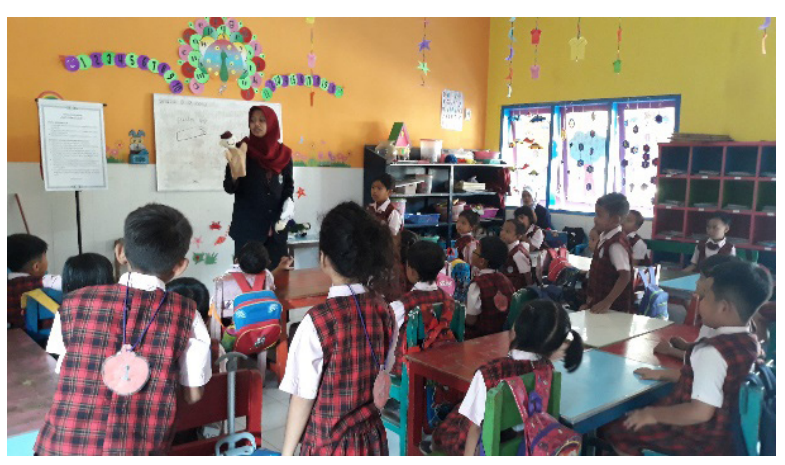

Gambar 4. Kegiatan Uji Coba Lapangan di Kelas B TK PKK Kelurahan Bandulan Kecamatan Sukun Kota Malang

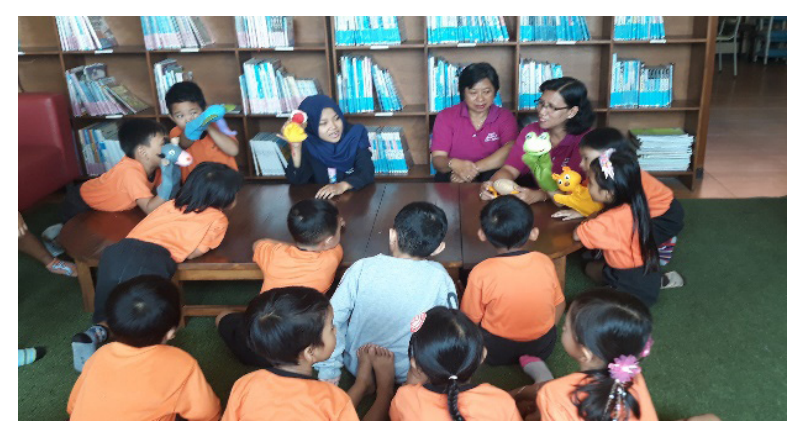

Gambar 5. Kegiatan Uji Coba Lapangan di Kelas B TK AGAPE Bandulan Kecamatan Sukun Kota Malang

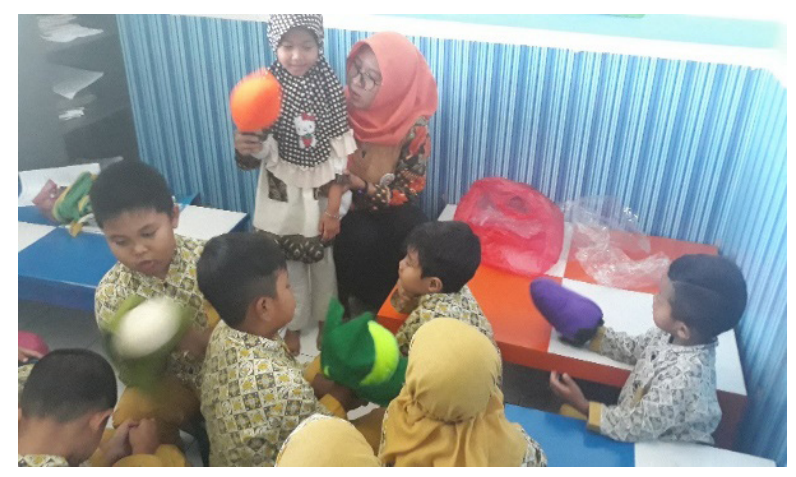

Gambar 6. Kegiatan Uji Coba Lapangan di Kelas B TK PLUS KIDS Kelurahan Bandulan

Kecamatan Sukun Kota Malang

Hasil analisis data uji coba lapangan (kelompok besar) dalam pengembangan media pembelajaran boneka dari bahan kain flanel di TK PKK, TK AGAPE, TK PLUS KIDS
Bandulan kecamatan Sukun kota Malang terkaitaspekkemudahandiperolehpersentase sebesar $80,55 \%$ anak mudah menggunakan media pembelajaran boneka dari bahan kain flanel, terkait aspek kemenarikan diperoleh persentase sebesar $100 \%$ anak tertarik menggunakan media pembelajaran boneka dari bahan kain flanel, serta terkait aspek keamanan diperoleh persentase sebesar $100 \%$ anak aman dalam menggunakan media pembelajaran boneka dari bahan kain flanel. .Berdasarkan keseluruhan data hasil uji coba lapangan(kelompok besar) diperoleh ratarata persentase sebesar $93,51 \%$, dari kriteria yang digunakan maka dapat dikatakan media pembelajaran boneka dari bahan kain flanel sangat valid atau layak digunakan

Tabel 3. Rekap Keseluruhan Data Hasil Uji Coba Kelompok Besar

\begin{tabular}{|c|c|c|}
\hline No. & $\begin{array}{l}\text { Evaluasi } \\
\text { TK PKK } \\
\text { TK AGAPE } \\
\text { TK PLU SKIDS }\end{array}$ & $\begin{array}{l}\text { RATA } \\
\text { RATA }\end{array}$ \\
\hline 1. & $\begin{array}{l}\text { Aspek Kemudahan } \\
83,33 \% \\
66,66 \% \\
91,66 \%\end{array}$ & $80,55 \%$ \\
\hline 2. & $\begin{array}{l}\text { Aspek Kemenarikan } \\
100 \% \\
100 \% \\
100 \%\end{array}$ & $100 \%$ \\
\hline \multirow[t]{5}{*}{3.} & $\begin{array}{l}\text { Aspek Keamanan } \\
100 \% \\
100 \% \\
100 \%\end{array}$ & $100 \%$ \\
\hline & $\begin{array}{l}\text { Jumlah } \\
283,33 \\
266,66 \\
291,66\end{array}$ & 280,55 \\
\hline & $\begin{array}{l}\text { Rata-rata } \\
94,44 \% \\
88,88 \% \\
97,22 \%\end{array}$ & $93,51 \%$ \\
\hline & $\begin{array}{l}\text { Jumlah } \\
280,55\end{array}$ & \\
\hline & $\begin{array}{l}\text { Rata-rata } \\
93,51 \%\end{array}$ & \\
\hline
\end{tabular}

Berdasarkan keseluruhan data hasil uji coba kelompok besar diperoleh rata-rata persentase 
sebesar 93,51\%, dari kriteria yang digunakan maka dapat dikatakan media pembelajaran boneka dari bahan kain flanel sangat valid atau layak digunakan. Dengan demikian dapat dikatakan media pembelajaran boneka dari bahan kain flanel layak digunakan untuk mengembangkan kemampuan bahasa ekspresif anak dalam bercerita.

\section{HASIL DAN PEMBAHASAN}

Atas dasar hasil penelitian awal, maka disusun rancangan produk pengembangan kemampuan bahasa ekspresif anak dalam bercerita berupa media pembelajaran boneka dari bahan kain flanel. Setelah rancangan dievaluasi oleh para ahli maka mendapatkan saran dan masukan sebagai meliputi. Kegiatan pembelajaran untuk mengembangkan kemampuan bahasa ekspresif anak dalam bercerita menggunakan media boneka dari bahan kain flanel sebaiknya untuk boneka jari tidak digunakan secara klasikal tapi secara kelompok dan untuk boneka tangan digunakan secara klasikal.

Boneka yang berbentuk manusia atau binatang agar dilengkapi dengan unsur hidung pada bagian wajah agar lebih terasa ekspresinya.

Ukuran lubang bagian bawah kepala boneka diameternya disesuaikan dengan ukuran jari-jari orang dewasa untuk boneka jari, dengan ukuran telapak tangan orang dewasa untuk boneka tangan, sehingga bisa cukup jika digunakan oleh guru maupun oleh anak. Sebaiknya bentuk boneka dari tema yang sama untuk boneka jari dibedakan sub-temanya dengan boneka tangan agar bervariasi dan fleksibel dalam pemanfaatannya.

Setelah dilakukan revisi terhadap rancangan produk, maka jadilah produk awal yang selanjutnya di uji cobakan. Pada uji coba kelompok kecil diperoleh persentase sebesar $83,32 \%$ anak mudah menggunakan media pembelajaran boneka dari bahan kain flanel, terkait aspek kemenarikan diperoleh persentase sebesar $98,05 \%$ anak tertarik menggunakan media pembelajaran boneka dari bahan kain flanel, serta terkait aspek keamanan diperoleh persentase sebesar $100 \%$ anak aman dalam menggunakan media pembelajaran boneka dari bahan kain flanel. Dari hasil uji coba kelompok kecil yang telah dilakukan, terdapat beberapa hal yang harus di revisi yaitu; boneka yang berbentuk manusia atau binatang dilengkapi dengan unsur hidung pada bagian wajah sehingga lebih terasa ekspresinya; ukuran lubang bagian bawah kepala boneka diameternya disesuaikan dengan ukuran jari-jari orang dewasa untuk boneka jari, dengan ukuran telapak tangan orang dewasa untuk boneka tangan, sehingga jadi cukup jika digunakan oleh guru maupun oleh anak menjadi longgar dan mudah dalam penggunaannya.

Pada uji coba lapangan (kelompok besar) diperoleh persentase sebesar $80,55 \%$ anak mudah menggunakan media pembelajaran boneka dari bahan kain flanel, terkait aspek kemenarikan diperoleh persentase sebesar $100 \%$ anak senang menggunakan media pembelajaran boneka dari bahan kain flanel, serta terkait aspek keamanan diperoleh persentase sebesar $100 \%$ anak aman dalam menggunakan media pembelajaran boneka dari bahan kain flanel.

Setelah melalui langkah-langkah sebagaimana tersebut diatas, maka media pembelajaran boneka dari bahan kain flanel yang dikembangkan layak dipergunakan dalam mengembangkan kemampuan bahasa ekspresif anak dalam bercerita.

Penelitian dan pengembangan ini menghasilkan produk "Media Pembelajaran Boneka dari bahan kain flanel" untuk mengembangkan kemampuan bahasa ekspresif anak dalam bercerita di kelompok B TK Gugus 9 yaitu TK PKK, TK AGAPE, TK PLUS KIDS Bandulan kecamatan Sukun kota Malang

Media pembelajaran boneka dari bahan kain flanel merupakan pengembangan dari media dua dimensi menjadi bentuk tiga dimensi karena biasanya guru hanya menggunakan papan tulis dan gambar dari buku dalam tema tertentu. Media pembelajaran boneka dari bahan kain flanel merupakan media pembelajaran kegiatan interaktif dalam kegiatan pembelajaran yang disesuaikan dengan situasi dan kondisi yang menampilkan bentuk-bentuk tiga dimensi dari tema keluarga, tanaman, dan binatang.

Hal ini sejalan dengan pendapat (Sudjana \& Rivai, 2010) menyatakan penggunaan media dalam pembelajaran bukan merupakan fungsi tambahan, tetapi memiliki fungsi sendiri 
sebagai alat bantu untuk mewujudkan situasi pembelajaran yang efektif; dan merupakan bagian yang integral dari keseluruhan situasi pembelajaran. Ini berarti bahwa media pembelajaran merupakan salah satu unsur yang harus dikembangkan guru.

Media pembelajaran boneka dari bahan kain flanel dirancang dan dibuat untuk digunakan sebagai alat permainan anak usia dini yang bersifat interaktif dalam pembelajaran bidang bahasa. Hal ini sejalan dengan pendapat (Musfiroh, 2008, 2014; Mutiah, 2015; Tedjasaputra, 2001) yang menyatakan alat permainan edukatif adalah alat permainan yang sengaja dirancang secara khusus untuk kepentingan pendidikan(Suyadi, 2009; Triharso, 2013). Sedangkan alat permainan edukatif untuk anak TK adalah alat permainan yang sengaja dirancang untuk tujuan meningkatkan aspek-aspek perkembangan anak TK (Ariyanti \& Muslimin, 2015).

Pemanfaatan alat permainan edukatif pada anak usia dini harus mendapatkan perhatian dari semua pihak. Para guru, kepala sekolah, pengawas dan pihak dinas pendidikan perlu melakukan berbagai terobosan untuk meningkatkan kreativitas dan produktivitas dalam merancang, mengembangkan dan memanfaatkan permainan edukatif untuk merangsang ketertarikan dan motivasi siswa dalam belajar. Keterarikan siswa terhadap alat dan bahan ajar yang digunakan akan melahirkan minat dan motivasi belajar. Hal tersebut akan mendorong kenyamanan belajar siswa. Boneka merupakan salah satu media dan bahan ajar yang disukai oleh para siswa (HS, Alfina, Sulaiman, \& Sahara, 2018).

Beberapa hasil penelitian terbaru mencoba melakukan terobosan dengan mengembangkan model-model boneka secara digital (Wohlwend \& Medina, 2017). Tentu hal tersebut dapat dilakukan pada situasi dan kondisi sekolah yang memungkinkan. Pertimbangan lainnya adalah para guru dituntut untuk meminimalkan penggunaan perangkat digital dalam aktivitas siswakarenahal-haltersebutdapatmenghambat perkembangan motorik anak (Haerani, Wiresanta, \& Septami, 2019; Setianingsih, 2018; Sodik, n.d.). Dengan demikian para guru perlu bijak dalam memilih jenis aktivitas dan media pembelajaran yang akan digunakan.
Maka pertimbangan kenyamanan, kemenarikan, kemudahan dan keamanan menjadi faktor penting yang harus diperhatikan.

\section{SIMPULAN}

Produk pengembangan berupa media pembelajaran boneka dari bahan kain flanel ini telah melalui proses yang cukup panjang. Proses tersebut dimulai dari penelitian awal, pembuatan rancangan produk hingga produk akhir terselesaikan yang memerlukan beberapa revisi dari para ahli (satu ahli pembelajaran anak usia dini, satu ahli media pembelajaran, dan satu ahli tema kegiatan pembelajaran anak usia dini) untuk mendapatkan produk yang maksimal, uji coba kelompok kecil, dan uji coba lapangan (kelompok besar). Setelah melalui serangkaian langkah penelitian dapat disimpulkan bahwa maka media pembelajaran boneka dari bahan kain flanel yang dikembangkan layak dipergunakan dalam mengembangkan kemampuan bahasa ekspresif anak dalam bercerita.

Penelitian ini menginspirasi para peneliti lain, para guru dan pemerhati pendidikan anak usia dini agar dapat memanfaatkan produk serupa untuk melatih kemampuan berkomunikasi anak usia 5-6 tahun.

\section{DAFTAR PUSTAKA}

AECT, T. F. (1977). The Definition of Educational. Terminology, Washington DC: AECT.

Akbar, S. (2013). Instrumen perangkat pembelajaran. Bandung: PT Remaja Rosdakarya.

Ardhana, W. (2002). Konsep Penelitian Pengembangan dalam Bidang Dunia Pendidikan dan Pembelajaran, Makalah Disajikan dalam Lokakarya Nasional Angkatan II Metodologi Penelitian Pengembangan Bidang Pendidikan dan Pembelajaran. Hotel Asida Batu. Malang.

Arief, S. (2009). Media Pendidikan, Pengertian, Pengembangan, dan Pemanfaatannya. Jakarta: PT. Rajagrafindo Persada.

Ariyanti, A., \& Muslimin, Z. I. (2015). Efektivitas Alat Permainan Edukatif (APE) Berbasis Media dalam Meningkatkan Kemampuan Berhitung pada Anak Kelas 2 di SDN 2 Wonotirto Bulu Temanggung. Jurnal Psikologi Tabularasa, 10(1). 
Arsyad, A. (2002). Media pembelajaran, edisi 1. Jakarta: PT. Raja Grafindo Persada, 36.

Bennett, N., Borg, W. R., \& Gall, M. D. (1984). Educational Research: An Introduction. BritishJournalofEducationalStudies,32(3), 274. https://doi.org/10.2307/3121583

Dini, D. P. P. A. U. (2015). Kurikulum Pendidikan Anak Usia Dini: Apa, Mengapa, dan Bagaimana. Jakarta: Kementrian Pendidikan dan Kebudayaan.

Gall, M. D., Borg, W. R., \& Gall, J. P. (2003). Educational research: An introduction. Longman Publishing.

Ghafur, A. (1998). Sumber Belajar. Yogyakarta.

Haerani, B., Wiresanta, L., \& Septami, B. L. (2019). Hubungan Durasi Bermain Gadged (Game Edukasi) Dengan Tingkat Perkembangan Anak Usia 4-6 Tahun Di TK Dahlia Darmaji. Jurnal Surya Mudal Jurnal STIKES Muhammadiyah Kendal, 1(2), 61-69.

HS, N. R. A. K., Alfina, F. T., Sulaiman, S., \& Sahara, M. (2018). Teaching Animal Vocabularies Using Doll As Media in TK Sakti Merisi. PROCEEDING International Conference Technopreneur and Education 2018, 1(1), 61-64.

Kustiawan, U. (2016). Pengembangan Media Pembelajaran Anak Usia Dini. Penerbit Gunung Samudera [Grup Penerbit PT Book Mart Indonesia].

Kustiawan, U. (2017). The Development of Diorama Learning Media Transportation Themes to Develop Language Skill Children's Group B. Research on Education and Media, 9(2), 26-31.

Kustiawan, U., Tweet, B. P. D. H. S., IImiah, K., Psikologi, F. P., Penelitian, L., Masyarakat, P. K., ... Elektronik, L. P. S. (2015). Media Pembelajaran Sekolah Inklusif. Malang: Universitas Negeri Malang.

Musfiroh, T. (2008). Cerdas melalui bermain. Jakarta: Grasindo.

Musfiroh, T. (2014). Bermain dan Permainan Anak.

Mutiah, D. (2015). Psikologi bermain anak usia dini. Kencana.

Pratiwi, W. (2017). Konsep bermain pada anak usia dini. TADBIR: Jurnal Manajemen Pendidikan Islam, 5(2), 106-117.

Ramadhani, P. K., \& Kustiawan, U. (2017). The Effect of the Big Book Media Usage to
Simple Sentences' Reading Ability for Third Grader with Intellectual Disability on Elementary School for Special Needs. Journal of ICSAR, 1(1), 42-45.

Sadiman, Arief S, Rahardjo, Haryono, Anung, \& R. (1986). Media Pendidikan. Jakarta: PT Raja Grafindo Persada.

Sadiman, A. (2010). Media pendidikan. Rajawali Pers.

Satrianawati. (2018). Media Dan Sumber Belajar. Yogyakarta: CV Budi Utama.

Setianingsih, S. (2018). Dampak Penggunaan Gadget Pada Anak Usia Prasekolah Dapat Meningkatan Resiko Gangguan Pemusatan Perhatian Dan Hiperaktivitas. Gaster: Jurnal Kesehatan. Retrieved from http://jurnal. stikes-aisyiyah.ac.id/index.php/gaster/ article/view/297

Setyosari, P. (2005). Media Pembelajaran. Malang: Elang Mas.

Sodik, M. A. (n.d.). Dampak Bermain Gadget Yang Berlebihan Pada Usia Dini.

Sudjana, N., \& Rivai, A. (2010). Media pengajaran. Bandung: Sinar Baru Algensindo.

Sudono, A. (1995). Alat Permainan dan Sumber Belajar TK. Jakarta: PPTA Dirjen Dikti.

Sugiyono. (2014). Metode Penelitian Kuantitatif, Kualitatif dan R\&D. Alfabeta. Bandung.

Sujiono, Y. N. (2009). Konsep dasar pendidikan anak usia dini.

Susilana, R., Si, M., \& Riyana, C. (2008). Media pembelajaran: hakikat, pengembangan, pemanfaatan, dan penilaian. CV. Wacana Prima.

Suyadi. (2009). Permainan Edukatif yang Mencerdaskan. Yogyakarta: Powerbook.

Tedjasaputra, M. S. (2001). Bermain, mainan dan permainan. Grasindo.

Triharso, A. (2013). Permainan kreatif dan edukatif untuk anak usia dini. Yogyakarta: CV Andi Offset.

Ulfa, S. (2017). Pemanfaatan Teknologi Bergerak Sebagai Media Pembelajaran Bagi Anak Usia Dini. Edcomtech Jurnal Kajian Teknologi Pendidikan. Retrieved from http://journal2. um.ac.id/index.php/edcomtech/article/ view/1783

Wohlwend, K. E., \& Medina, C. L. (2017). Monster High: Converging Imaginaries of Girlhood in Tweens' Digital Doll Play. In Literacy Lives in Transcultural Times (pp. 75-88). Routledge. 